\title{
Satellite traces, range spread-F occurrence, and gravity wave propagation at the southern anomaly crest
}

\author{
M. A. Cabrera ${ }^{1,2}$, M. Pezzopane ${ }^{3}$, E. Zuccheretti ${ }^{3}$, and R. G. Ezquer ${ }^{1,2,4}$ \\ ${ }^{1}$ CIASUR, Facultad Regional Tucumán, Universidad Tecnológica Nacional, Tucumán, Argentina \\ ${ }^{2}$ Laboratorio de Ionósfera, Dpto. de Física, Universidad Nacional de Tucumán, Argentina \\ ${ }^{3}$ Istituto Nazionale di Geofisica e Vulcanologia, Rome, Italy \\ ${ }^{4}$ Consejo Nacional de Investigaciones Científicas y Técnicas (CONICET), Buenos Aires, Argentina
}

Received: 22 December 2009 - Revised: 26 March 2010 - Accepted: 22 April 2010 - Published: 18 May 2010

\begin{abstract}
Range spread-F (RSF) and occurrence of "satellite" traces prior to RSF onset were studied at the southern peak of the ionospheric equatorial anomaly (EA). Ionograms recorded in September 2007 at the new ionospheric station of Tucumán, Argentina $\left(26.9^{\circ} \mathrm{S}, 294.6^{\circ} \mathrm{E}\right.$, dip latitude $\left.15.5^{\circ} \mathrm{S}\right)$, by the Advanced Ionospheric Sounder (AIS) developed at the Istituto Nazionale di Geofisica e Vulcanologia (INGV), were considered.

Satellite traces (STs) are confirmed to be a necessary precursor to the appearance of an RSF trace on the ionograms. Moreover, an analysis of isoheight contours of electron density seems to suggest a relationship between RSF occurrence and gravity wave $(\mathrm{GW})$ propagation.
\end{abstract}

Keywords. Ionosphere (Equatorial ionosphere; Ionosphereatmosphere interactions; Ionospheric irregularities)

\section{Introduction}

Spread-F signatures on ionograms are the manifestation of ionospheric irregularities in the F-region. Although spread$\mathrm{F}$ is an impediment to perform an accurate scaling of ionograms it gives valuable information on the occurrences, both geographical and temporal, of F-layer irregularities. These irregularities cause rapid changes in both the amplitude and phase of radio signals passing through them, producing scintillations that seriously degrade trans-ionospheric radio communications. Since scintillation studies are essential for developing forecasting models, it is very important to improve our knowledge of the behavior of the irregularities that cause scintillations. The spreading echo is usually categorized into

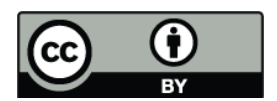

Correspondence to: M. Pezzopane (michael.pezzopane@ingv.it) two main types, the RSF and the frequency spread-F (FSF) (Piggott and Rawer, 1972), even though several authors perform further subdivisions into RSF-I, RSF-II, FSF-I, and FSF-II (Chen et al., 2006).

The equatorial belt between magnetic latitudes $20^{\circ} \mathrm{N}$ and $20^{\circ} \mathrm{S}$ is a well defined region where spread-F is a normal occurrence and has been described and studied in depth since the 1950s (Wright, 1959; Cohen and Bowles, 1961; Balsley et al., 1972; Aarons, 1978; Fejer et al., 1979; Argo et al., 1986; Mendillo et al., 1992; Whalen, 2000; McNamara et al., 2008). This is because, while the post-sunset rise (PSSR) of the equatorial $\mathrm{F}$ layer is well correlated climatologically with the equatorial spread-F (ESF) (Fejer et al., 1999; Hysell and Burcham, 2002), the day-to-day variability of ESF remains a long-standing enigma.

Tsunoda (2005, 2008, 2009) and Tsunoda and Ecklund (2007) pointed out that large-scale wave structure (LSWS), in the bottomside F-layer, is an important contributor to be taken into account in solving this puzzle. These authors showed how the LSWS upwelling may evolve into a plume and hence into an equatorial plasma bubble (EPB), and they demonstrated, using incoherent scatter radar data and ionosonde data from Kwajalein Atoll, Marshall Islands, that STs and multi-reflected echoes can be considered as ionogram signatures for LSWS. Satellite traces in equatorial ionograms appear as one or more quasi replicas of the Flayer trace at displaced virtual heights prior to the ESF onset, and are probably produced by oblique reflections from upwelling walls, that is, corrugations in the isodensity surfaces. This issue was very well illustrated by Tsunoda (2008) who provided further evidence, besides those advanced by Wright (1959), Lyon (1961), Abdu et al. (1981), and McNamara et al. (2008), that STs are a characteristic precursor of ESF over the equatorial belt.

Published by Copernicus Publications on behalf of the European Geosciences Union. 
Table 1. UT start and end of RSF at Tucumán on September 2007.

\begin{tabular}{lcccc}
\hline Day & Ap & ST start & RSF start & RSF end \\
\hline 4 September 2007 (day 247) & 5 & $04: 50$ & $05: 10$ & $06: 45$ \\
5 September 2007 (day 248) & 10 & No ST & $04: 55$ & $07: 10$ \\
11 September 2007 (day 254) & 2 & $03: 25$ & $04: 15$ & $06: 00$ \\
15 September 2007 (day 258) & 4 & $03: 20$ & $04: 50$ & $06: 00$ \\
19 September 2007 (day 262) & 3 & $03: 05$ & $04: 20$ & $05: 30$ \\
23 September 2007 (day 266) & 16 & No ST & $08: 55$ & $09: 55$ \\
\hline
\end{tabular}

Fagundes et al. (2009a, b), as well, showed that PSSR can be strongly modulated by traveling planetary wave ionospheric disturbance oscillations.

Abdu et al. (1982) were the first to illustrate ST occurrence in ionograms, and its possible relationship with RSF occurrence, near the southern crest of the equatorial anomaly.

The role played by large-scale horizontal structures in interpreting day-to-day ESF variability was also investigated by Fukao et al. (2006). They assumed that the longitudinal structures generated by GWs may significantly modify the ionospheric plasma, and they found that multiple EPBs are often formed at distances of several hundreds of $\mathrm{km}$ from each other.

With regard to GW propagation features, Klausner et al. (2009) presented a very good work illustrating its seasonal variation at the southern crest of the equatorial anomaly.

This work represents one more contribution to study concurrently ST occurrence, RSF day-to-day variability, and $\mathrm{GW}$ propagation at the southern crest of the EA, in order to look for a possible relationship between them. Our results show that RSF signatures on the ionograms do not seem to be due to equatorial plasma bubbles coming from the magnetic equator where they were generated around sunset, but rather to plasma instabilities that were locally generated.

\section{Experiment}

The ionograms used were recorded in September 2007, a year of low solar activity, at the new ionospheric station of Tucumán, Argentina $\left(26.9^{\circ} \mathrm{S}, 294.6^{\circ} \mathrm{E}\right.$, dip latitude $\left.15.5^{\circ} \mathrm{S}\right)$, where an AIS-INGV ionosonde was installed in August 2007 (Pezzopane et al., 2007). The corresponding data is visible at the site www.eswua.ingv.it (Romano et al., 2008). Data from September 2007 was considered because at that time the sounding repetition rate was set to $5 \mathrm{~min}$ which is more suitable for tracking satellite trace time evolution, which may be of the order of a few minutes. The sweeping frequency range was set from $1.5 \mathrm{MHz}$ to $15 \mathrm{MHz}$.

\section{Analysis and results}

The Tucumán ionograms recorded in September 2007 were analyzed to determine the occurrence of RSF echoes. Our study was limited to RSF echoes because STs are found to be necessary precursors to the formation of irregularities that give rise to RSF; on the contrary FSF are observed under different circumstances and with different occurrence probabilities (Abdu et al., 1981; Fagundes et al., 2007; Lee et al., 2009).

Table 1 shows the 6 days on which RSF appeared on the ionogram (in Fig. 1 the RSF development occurred on 4 September 2007), with the corresponding universal time (UT) start and end, and it also shows whether STs are visible before the RSF appearance, with the UT of their first occurrence. The second column gives the planetary Ap index.

For all 6 cases listed in Table 1 it is worth noting that, independently of ST appearance, a diffuse trace of partially formed spread-F is already present in the second order mode (see Fig. 1a and b). However, the most important thing to note in Table 1 is that all the RSF signatures appear well after the local sunset, which in this month occurs on average at 19:00 local time (LT=UT-4), and also well after the time an EPB, that was formed at sunset at the dip equator, takes to drift to the EA, $\sim 95 \mathrm{~min}$ as illustrated in a very comprehensive way by Whalen (2000). This suggests the two following considerations: 1) the observed RSF do not seem to be signature of EPBs generated around sunset at the magnetic equator; instead they may be considered signatures of plasma instabilities that were locally generated; 2) the PSSR, that can extend under the southern crest of the EA as was shown by Klausner et al. (2009) and by Abdu et al. (2009), cannot be considered itself as the only cause of RSF appearance on the ionogram, and a triggering process associated with PSSR is needed to cause instabilities responsible for RSF development. In support of this argument, Fig. 2 shows the manually scaled values of the nighttime $h^{\prime} \mathrm{F} 2$ (the height of the base of the F2 layer) at a frequency of $3 \mathrm{MHz}\left[h^{\prime}(3 \mathrm{MHz})\right]$ for nights with (4, 5, and 19 September 2007, day 247, 248, and 262, respectively) and without (7 September 2007, day 250) RSF. The most pronounced PSSR is on day 250, a day without RSF. This highlights how PSSR cannot be considered itself 

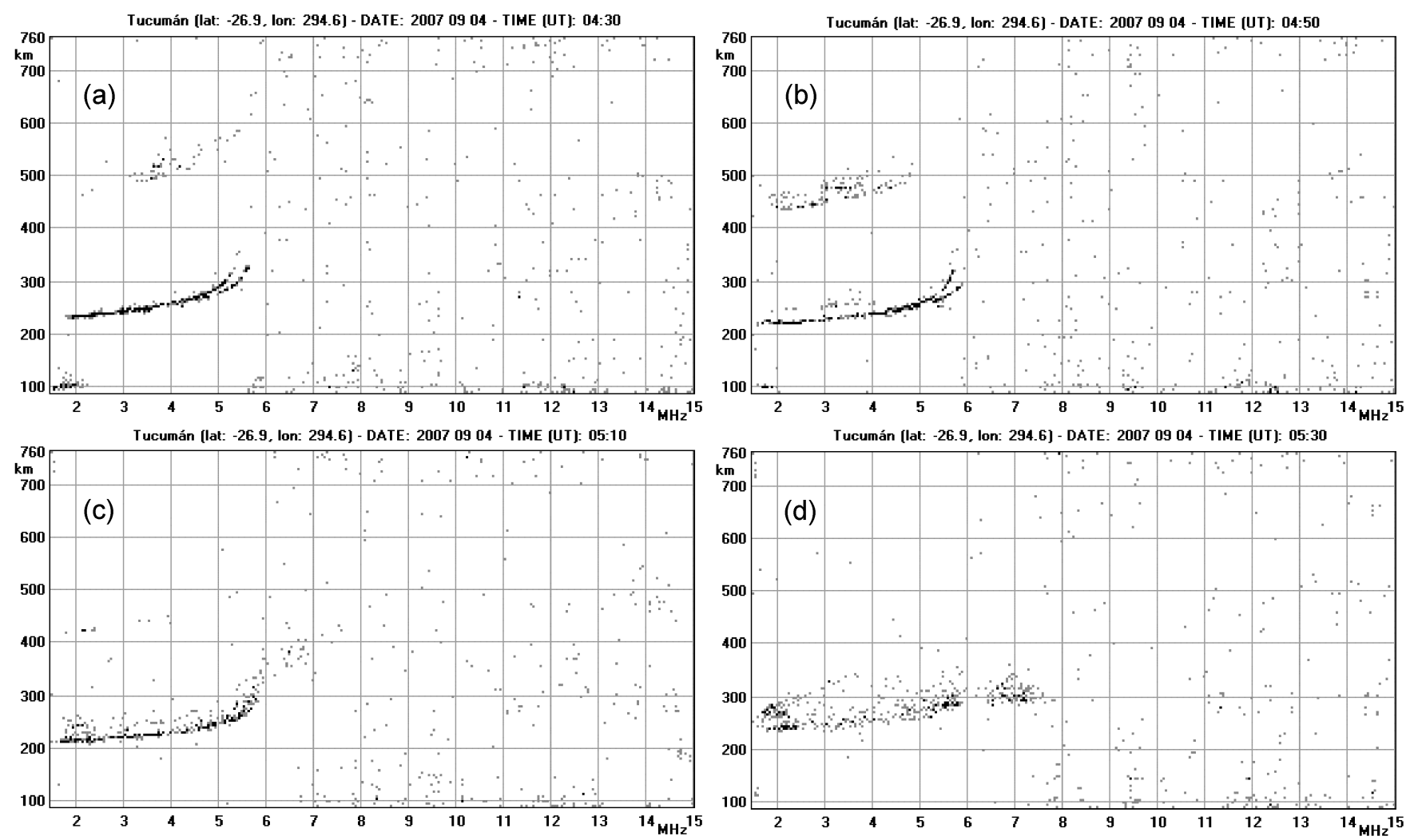

Fig. 1. Sequence of ionograms recorded on 4 September 2007 showing (a) diffuse trace in the second order mode, (b) ST appearance adjacent to the low-frequency end of the first order mode, (c) RSF commencement, and (d) RSF fully developed.

the only factor responsible for RSF development, and that associated triggering processes seem to be needed.

Kelley et al. (1981) presented evidence for GW initiation of ESF at the magnetic equator. Huang and Kelly (1997), still at the magnetic equator, illustrated a theoretical study describing GW seeding as a cause for the onset of ESF. Recently, Abdu et al. (2009) analyzing the F-layer height oscillations recorded by the digisonde at Fortaleza highlighted the role of GWs in causing density perturbations responsible for spread-F signatures also at EA latitudes.

In agreement with these studies, once the days on which RSF occurred were isolated, the corresponding ionogram traces were manually digitized obtaining an electron density profile $\left(N, h^{\prime}\right)$ for each ionogram, where $N$ is the electron density and $h^{\prime}$ the virtual height of reflection. Then the inversion from the profile $\left(N, h^{\prime}\right)$ to the profile $(N, h)$, where $h$ is the true height of reflection, was performed using the POLAN inversion technique (Titheridge, 1988).

Hence, from the profiles $(N, h)$ isoheight curves $N(h=$ const $=210,220,230,240,250 \mathrm{~km})$ were obtained. In Fig. 3a, b, and d these curves are plotted from 00:00 to 08:00 UT (20:00 to 04:00 LT) for days 247, 248, and 262, respectively. Attention was focused on this time interval because it comprises both ST and subsequent RSF appearances. Quasi-periodic oscillations are visible for day 247 from 01:00 to 03:00 UT (21:00 to 23:00 LT), and for day 262 from 00:00 to 01:00 UT (20:00 to 21:00 LT). Maximum and minimum $N$ variations occur first at $250 \mathrm{~km}$ and then at lower heights, showing a downward phase propagation which is characteristic of GW propagation in the ionospheric F-region (Hines, 1960). On the contrary, for day 248 (occurrence of RSF but not of STs) no quasi-periodic oscillations are markedly visible. For an overall view of the problem, ionograms referring to days not characterized by RSF occurrence were also manually digitized, and Fig. $3 \mathrm{c}$ shows the isoheight curves for one of these days (250). Again in this case no quasi-periodic oscillations are visible.

Using the isoheight curves it is possible to deduce the GW period $T$ by simply inferring the time interval of two consecutive peaks or valleys for a specified height, and the vertical phase velocity $V_{\mathrm{z}}$ using the peak of two consecutive heights, as illustrated in Fig. 4 for day 247; the vertical wavelength $\lambda_{\mathrm{z}}=V_{\mathrm{z}} T$ is then obtained. For days 247 and 262 shown in Fig. $3 \mathrm{a}$ and $\mathrm{d}$ the following values $T_{(247)} \sim 1 \mathrm{~h}$, $V_{\mathrm{z}(247)} \sim 40 \mathrm{~m} / \mathrm{s}, \lambda_{\mathrm{z}(247)} \sim 144 \mathrm{~km}, T_{(262)} \sim 30 \mathrm{~m}, V_{\mathrm{z}(262)} \sim$ $40 \mathrm{~m} / \mathrm{s}$, and $\lambda_{\mathrm{z}(262)} \sim 80 \mathrm{~km}$ were obtained, which are consistent with the analysis performed by Klausner et al. (2009) using a digisonde at São José dos Campos (SJC, $23.2^{\circ} \mathrm{S}$, $45.9^{\circ} \mathrm{W}$, dip latitude $17.6^{\circ}$ ), Brazil, under the southern crest of the EA during low solar activity. 

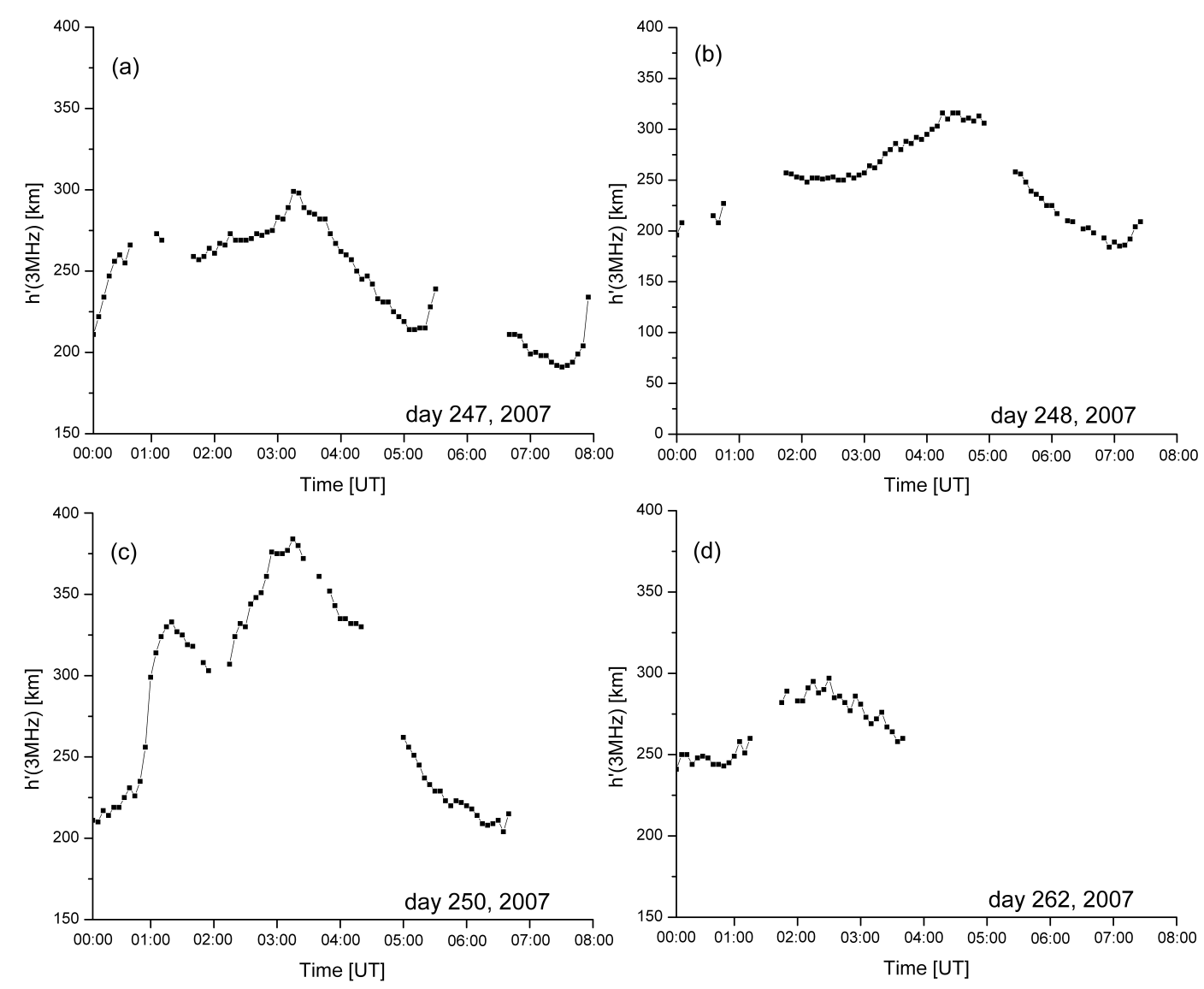

Fig. 2. Scaled virtual heights at $3 \mathrm{MHz}\left[h^{\prime}(3 \mathrm{MHz})\right]$ for days 247,248 , and 262, 2007, with RSF, and day 250, 2007, without RSF.

\section{Discussion and summary}

This work represented a contribution to analyze concurrently ST occurrence, RSF day-to-day variability, and GW propagation at the southern crest of the equatorial anomaly. In order to do this, RSF occurrence was investigated using ionosonde data recorded in September 2007 at the new ionospheric station of Tucumán, and 6 cases of RSF signatures were found on 6 different days.

RSF signatures at low latitudes appearing later at night are usually thought as due to irregularities created elsewhere, at the dip equator, and then drifted to higher latitudes (Valladares et al., 1983; McNamara et al., 2008).

However, the UT start and end shown in Table 1 suggest that RSF may not be signatures of EPBs generated around sunset at the magnetic equator but rather signatures of plasma instabilities that were locally generated. In support of this idea, Lee et al. (2009) found that the possibility for the Fregion irregularities to extend from the dip equator to the EA crest is about $50 \%$ during high solar activity, and Sahai et al. (2000), using the OI $630 \mathrm{~nm}$ all-sky imaging system, found that EPBs reaching very high altitudes at the dip equator are much fewer during low solar activity than during high solar activity. Hence, F-region irregularities have a very low probability of propagating to EA latitudes during low solar activity. Again, Dabas et al. (2007) found that over low latitude station Delhi, India, spread-F occurrence seems to be caused by irregularities generated locally, and that in addition to $\boldsymbol{E} \times \boldsymbol{B}$ some other controlling parameters like gravity waves or neutral winds are also playing an important role.

Analyzing $N(h=$ const) curves, a GW propagation signature was found for days characterized by both RSF and ST occurrences (Fig. 3a and d), and the corresponding parameters $\left(T, V_{\mathrm{z}}\right.$, and $\left.\lambda_{\mathrm{z}}\right)$ are in agreement with those found by Klausner et al. (2009). The UT of such signatures suggests that for these cases GWs are excited by the solar terminator passage (Somsikov and Ganguly, 1995; Galushko et al., 1998). On the other days, not characterized by RSF occurrence (Fig. 3c) or characterized by RSF occurrence but not by ST appearance (Fig. 3b), a GW propagation signature was not found.

The identification of GWs as a condition for RSF development requires the detection of these waves prior the RSF onset. Looking at the UT of RSF occurrence shown in Table 1 and at the UT of GW propagation, it seems that for the RSF cases on 4, 11, 15, and 19 September 2007 the irregularities 

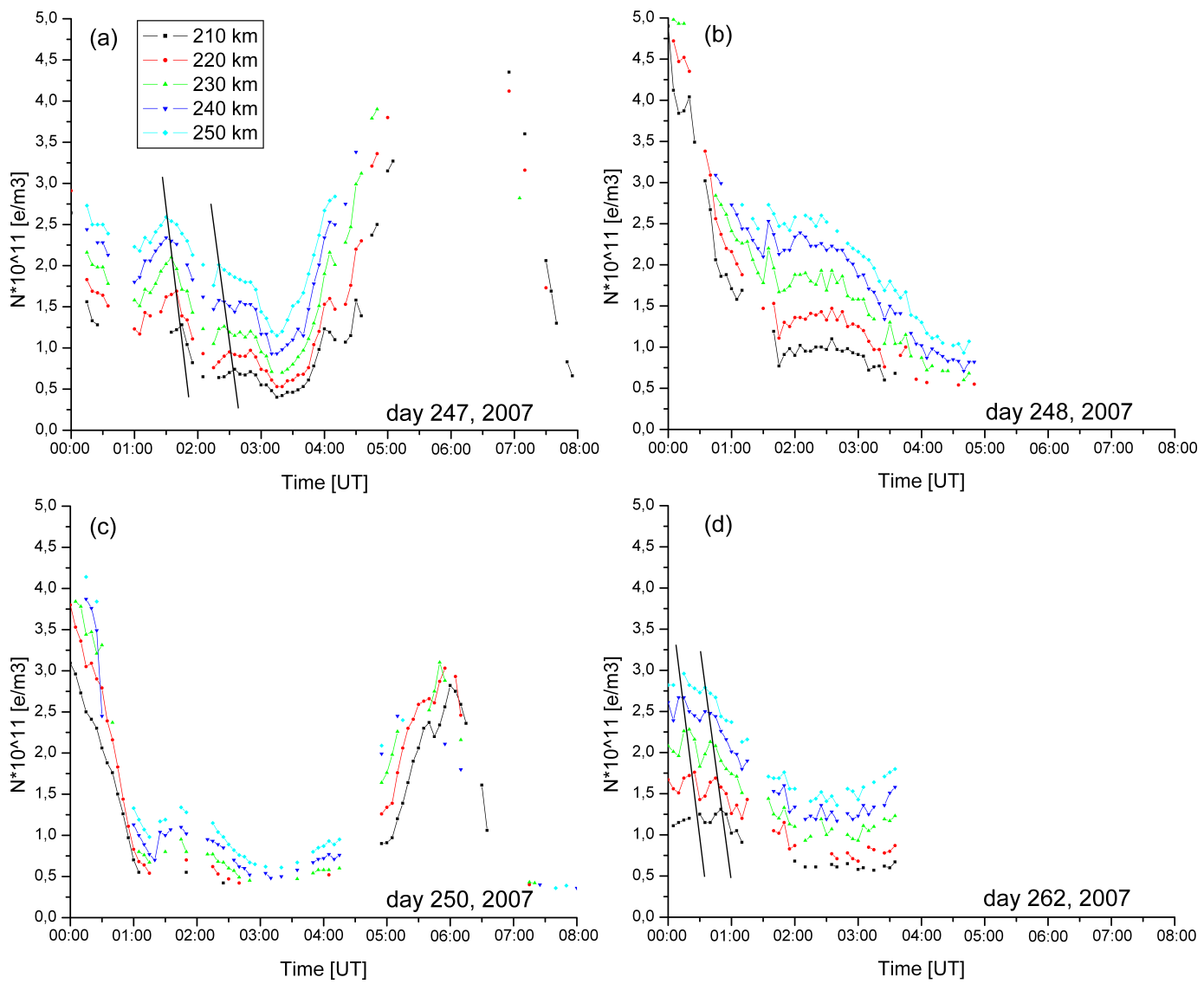

Fig. 3. Electron density variations for real heights 210, 220, 230, 240, and $250 \mathrm{~km}$ for days (a) 247, (b) 248, (c) 250, and (d) 262 , 2007 from 00:00 to 08:00 UT (20:00 to 04:00 LT). Data gap characterizing (a), (b), and (d) is due to RSF occurrence which avoided the operator digitized the trace.

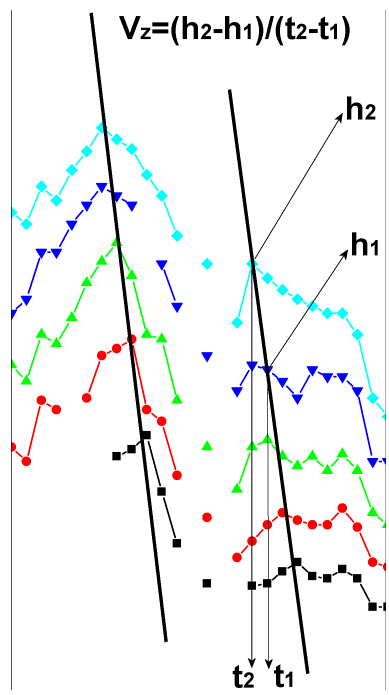

Fig. 4. Enlargement of Fig. 3a from 01:00 to 03:00 UT (21:00 to 23:00 LT) to show how $V_{\mathrm{Z}}$ is calculated. responsible for RSF signatures on the ionogram are generated locally. In fact, in these cases STs, always higher than the main trace, are due to corrugation in the isodensity surfaces caused by GW propagation which, in turn, can be considered to be the mechanism that, amplifying the post sunset seeding sources of irregularities, like the appearance of an eastward electric field during PSSR of the F-layer (Fejer et al., 1999; Hysell and Burcham, 2002; Klausner et al., 2009), gives rise to the instabilities responsible for the RSF signatures occurring on the ionogram.

The triggering process responsible for instabilities development accountable for RSF appearance on 5, and 23 September 2007 is of another kind, certainly not related to magnetic phenomena, like a penetrating magnetospheric electric field, because the magnetic activity was low as illustrated in Table 1.

In order to strengthen our idea, we considered also ionograms recorded in the same period at Palmas (PAL, $10.2^{\circ} \mathrm{S}$, $48.2^{\circ} \mathrm{W}$, dip latitude $5.7^{\circ} \mathrm{S}$ ) and SJC, Brazil, that are located in the same sector as Tucumán. Tables 2 and 3 show the details of the spread-F observation at PAL and SJC respectively, likewise Table 1 for Tucumán. They show that 
Table 2. UT start and end of spread-F at Palmas on September 2007.

\begin{tabular}{lcccc}
\hline Day & Ap & ST start & SF start & SF end \\
\hline 4 September 2007 (day 247) & 5 & No ST & Strong Es & Strong Es \\
5 September 2007 (day 248) & 10 & No ST & $05: 45$ (FSF) & 06:55 (FSF) \\
11 September 2007 (day 254) & 2 & 01.55 & $02: 25$ (RSF) & 05:00 (FSF) \\
15 September 2007 (day 258) & 4 & No ST & $01: 15$ (RSF) & $04: 55$ (FSF) \\
19 September 2007 (day 262) & 3 & No ST & $01: 45$ (RSF) & $03: 00$ (RSF) \\
23 September 2007 (day 266) & 16 & 00.05 & $00: 25$ (RSF) & $07: 30$ (FSF) \\
\hline
\end{tabular}

Table 3. UT start and end of spread-F at São José dos Campos on September 2007.

\begin{tabular}{lcccc}
\hline Day & Ap & ST start & SF start & SF end \\
\hline 4 September 2007 (day 247) & 5 & No ST & $05: 55$ (FSF) & 06:10 (FSF) \\
5 September 2007 (day 248) & 10 & No data & No data & No data \\
11 September 2007 (day 254) & 2 & No ST & $02: 15$ (FSF) & $05: 45$ (FSF) \\
15 September 2007 (day 258) & 4 & No ST & $01: 15$ (FSF) & $06: 45$ (RSF) \\
19 September 2007 (day 262) & 3 & No ST & No SF & No SF \\
23 September 2007 (day 266) & 16 & No ST & 08:05 (FSF) & $08: 45$ (FSF) \\
\hline
\end{tabular}

also observation carried out at PAL and SJC, Brazil, exhibit spread-F phenomena during the same period considered for Tucumán. Since PAL and SJC are located in the same sector as Tucumán, this at first sight would suggest that spreadF phenomena observed at Tucumán are due to irregularities created at the dip equator, by making it difficult to accept they are generated locally. Anyway, analyzing more deeply Tables 1 and 3, that is ionograms recorded at the two ionospheric stations under the southern equatorial anomaly, one can see that most of spread-F occurred at SJC are of FSF type and, moreover, no satellite traces are observed. Since FSF signatures, compared to RSF, are observed under different circumstances and with different occurrence probabilities (Lee et al., 2009), this means that spread-F observed at Tucumán and SJC could be due to different mechanisms. On the other hand, the lack of satellite trace observations at SJC could mean that there isodensity contours are not corrugate and consequently that ionospheric plasma, at heights typical of the F-layer, is not suffering a wave perturbation, like instead it seems to be at Tucumán.

Moreover, the distance in longitude between Tucumán and São José dos Campos is about $1000 \mathrm{~km}$ and Fukao et al. (2006) showed that multiple plasma bubbles are often generated at distances from each other of $370-1000 \mathrm{~km}$ in longitude.

Our analysis therefore showed that RSF occurrence at the southern peak of the EA, heralded tens of minutes in advance by ST appearance, seems to be related to GW propagation through the F-region triggered by the solar terminator. In these cases STs could be considered as the indicator of GW propagation which, in turn, along with the PSSR seeding source, causes the development of the instabilities responsible for RSF signatures on the ionogram. Moreover, when RSF does not occur, no marked GW propagation is noted when analyzing isoheight curves.

At this stage, it is worth mentioning that recently Pimenta et al. (2008) observed dark band structures (optical measurements of medium-scale traveling ionospheric disturbances), presumably generated at mid latitude, that after having propagated towards low latitude they generated spread-F phenomena.

However, as was already highlighted by Saito and Maruyama (2007), a longitudinal chain of ionospheric observations with a resolution smaller than the scale size of the longitudinal ionospheric structure would be desirable.

In addition, to improve the knowledge of this ionospheric phenomenon, further analyses of larger datasets, for other solar activity and magnetic conditions, are necessary.

Acknowledgements. The authors gratefully acknowledge P. R. Fagundes for his helpful suggestions and for kindly providing ionospheric data for Palmas and São José dos Campos, Brazil.

Topical Editor K. Kauristie thanks P. R. Fagundes and another anonymous referee for their help in evaluating this paper. 


\section{References}

Aarons, J., Buchaw, J., Basu, S., and McClure, J. P.: The localized origin of equatorial $\mathrm{F}$ region irregularity patches, J. Geophys. Res., 83, 1659-1664, 1978.

Abdu, M. A., Batista, I. S., and Bittencourt, J. A.: Some characteristics of spread $\mathrm{F}$ at the magnetic equatorial station Fortaleza, J. Geophys. Res., 86, 6836-6842, 1981.

Abdu, M. A., Batista, I. S., Kantor, I. J., and Sobral, J. H. A.: Gravity wave induced ionization layers in the night F-region over Cachoeira Paulista $\left(22^{\circ} \mathrm{S}, 45^{\circ} \mathrm{W}\right)$, J. Atmos. Terr. Phys., 44, 759 767, 1982

Abdu, M. A., Alam Kherani, E., Batista, I. S., de Paula, E. R., Fritts, D. C., and Sobral, J. H. A.: Gravity wave initiation of equatorial spread $\mathrm{F} /$ plasma bubble irregularities based on observational data from the SpreadFEx campaign, Ann. Geophys., 27, 2607-2622, doi:10.5194/angeo-27-2607-2009, 2009.

Argo, P. E. and Kelley, M. C.: Digital ionosonde observations during equatorial spread F, J. Geophys. Res., 91, 5539-5555, 1986.

Balsley, B. B., Haerendel, G., and Greenwald, R. A.: Equatorial spread F: Recent observations and a new interpretation, J. Geophys. Res., 77, 5625-5628, 1972.

Chen, W. S., Lee, C. C., Liu, J. Y., Chu, F. D., and Reinisch, B. W.: Digisonde spread F and GPS phase fluctuations in the equatorial ionosphere during solar maximum, J. Geophys. Res., 111, A12305, doi:10.1029/2006JA011688, 2006.

Cohen, R. and Bowles, K. L.: On the nature of equatorial spread F, J. Geophys. Res., 66, 1081-1106, 1961.

Dabas, R. S., Das, R. M., Sharma, K., Garg, S. C., Devasia, C. V., Subbarao, K. S. V., Niranjan, K., and Rama Rao, P. V. S.: Equatorial and low latitude spread-F irregularity characteristics over the Indian region and their prediction possibilities, J. Atmos. Sol. Terr. Phys., 69, 685-696, doi:10.1016/j.jastp.2007.01.002, 2007.

Fagundes, P. R., Klausner, V., Sahai, Y., Pillat, V. G., BeckerGuedes, F., Bertoni, F. C. P., Bolzan, M. J. A., and Abalde, J. R.: Observations of daytime F2-layer stratification under the southern crest of the equatorial ionization anomaly region, J. Geophys. Res., 112, A04302, doi:10.1029/2006JA011888, 2007.

Fagundes, P. R., Bittencourt, J. A., Abalde, J. R., Sahai, Y., Bolzan, M. J. A., Pillat, V. G., and Lima, W. L. C.: F layer postsunset height rise due to electric field prereversal enhancement: 1. Traveling planetary wave ionospheric disturbance effects, J. Geophys. Res., 114, A12321, doi:10.1029/2009JA014390, 2009a.

Fagundes, P. R., Abalde, J. R., Bittencourt, J. A., Sahai, Y., Francisco, R. G., Pillat, V. G., and Lima, W. L. C.: F layer postsunset height rise due to electric field prereversal enhancement: 2 . Traveling planetary wave ionospheric disturbances and their role on the generation of equatorial spread F, J. Geophys. Res., 114, A12322, doi:10.1029/2009JA014482, 2009b.

Fejer, B. G., Farley, D. T., Woodman, R. F., and Calderon, C.: Dependence of equatorial $\mathrm{F}$ region vertical drift on season and solar cycle, J. Geophys. Res., 84, 5792-5796, 1979.

Fejer, B. G., Scherliess, L., and de Paula, E. R.: Effects of the vertical plasma drift velocity on the generation and evolution of equatorial spread F, J. Geophys. Res., 104, 19859-19869, 1999.

Fukao, S., Yokoyama, T., Tayama, T., Yamamoto, M., Maruyama, T., and Saito, S.: Eastward traverse of equatorial plasma plumes observed with the Equatorial Atmosphere Radar in Indonesia, Ann. Geophys., 24, 1411-1418, doi:10.5194/angeo-24-1411-
2006, 2006.

Galushko, V. G., Paznukhov, V. V., Yampolski, Y. M., and Foster, J. C.: Incoherent scatter radar observations of AGW/TID events generated by the moving solar terminator, Ann. Geophys., 16, 821-827, doi:10.5194/angeo-16-821-1998, 1998.

Hines, C. O.: Internal atmospheric gravity waves at ionospheric heights, Can. J. Phys., 38, 1441-1481, 1960.

Huang, C. S. and Kelly, M. C.: Nonlinear evolution of equatorial spread F 2. Gravity Wave seeding of Rayleigh-Taylor instability, J. Geophys. Res., 101, 293-302, 1996.

Hysell, D. L. and Burcham, J.: Long term studies of equatorial spread $\mathrm{F}$ using the JULIA radar at Jicamarca, J. Atmos. Sol. Terr. Phys., 64, 1531-1543, 2002.

Kelley, M. C., Larsen, M. F., and Lahoz, C.: Gravity wave initiation of equatorial spread F: a case study, J. Geophys. Res., 86, 90879100, 1981.

Klausner, V., Fagundes, P. R., Sahai, Y., Wrasse, C. M., Pillat, V. G., and Becker-Guedes, F.: Observations of GW/TID oscillations in the F2 layer at low latitude during high and low solar activity, geomagnetic quiet and disturbed periods, J. Geophys. Res., 114, A02313, doi:10.1029/2008JA013448, 2009.

Lee, C. C., Chu, F. D., Chen, W. S., Liu, J. Y., Su, S. Y., Liou, Y. A., and Yu, S. B.: Spread F, GPS phase fluctuations, and plasma bubbles near the crest of equatorial ionization anomaly during solar maximum, J. Geophys. Res., 114, A08302, doi:10.1029/2009JA014195, 2009.

Lyon, A. J., Skinner, N. J., and Wright, R. W.: Equatorial spread-F at Ibadan, Nigeria, J. Atmos. Terr. Phys., 21, 100-119, 1961.

McNamara, L. F., Retterer, J. M., Abdu, M. A., Batista, I. N., and Reinisch, B. W.: F2 Peak parameters, drifts and spread $F$ derived from digisonde ionograms for the COPEX campaign in Brazil, J. Atmos. Sol. Terr. Phys., 70, 1144-1158, doi:10.1016/j.jastp.2008.02.001, 2008.

Mendillo, M., Baumgardner, J., Pi, X., Sultan, P. J., and Tsunoda, R. T.: Onset conditions for equatorial spread-F, J. Geophys. Res., 97, 13865-13875, 1992.

Pezzopane, M., Zuccheretti, E., Bianchi, C., Scotto, C., Zolesi, B., Cabrera, M. A., and Ezquer, R. G.: The new ionospheric station of Tucumán: first results, Ann. Geophys.-Italy, 50(3), 483-492, 2007.

Piggott, W. R. and Rawer, K.: URSI Handbook of Ionogram Interpretation and Reduction, 2nd ed., 325 pp., Elsevier, New York, 1972.

Pimenta, A. A, Kelley, M. C., Sahai, Y., Bittencourt, J. A., and Fagundes, P. R.: Thermospheric dark band structures observed in all-sky OI $630 \mathrm{~nm}$ emission images over the Brazilian low-latitude sector, J. Geophys. Res., 113, A01307, doi:10.1029/2007JA012444, 2008.

Romano, V., Pau, S., Pezzopane, M., Zuccheretti, E., Zolesi, B., De Franceschi, G., and Locatelli, S.: The electronic Space Weather upper atmosphere (eSWua) project at INGV: advancements and state of the art, Ann. Geophys., 26, 345-351, doi:10.5194/angeo26-345-2008, 2008.

Sahai, Y., Fagundes, P. R., and Bittencourt, J. A.: Transequatorial Fregion ionospheric plasma bubbles: solar cycle effects, J. Atmos. Terr. Phys., 62(15), 1377-1383, 2000.

Saito, S. and Maruyama, T.: Large-scale longitudinal variation in ionospheric height and equatorial spread $\mathrm{F}$ occurrences observed by ionosondes, Geophys. Res. Lett., 34, L16109, 
doi:10.1029/2007GL030618, 2007.

Somsikov, V. M. and Ganguly, B.: On the formation of atmospheric inhomogeneities in the solar terminator region, J. Atmos. Terr. Phys., 57(12), 1513-1523, 1995.

Titheridge, J. E.: The real height analysis of ionograms: a generalized formulation, Radio Sci., 5, 831-849, 1988.

Tsunoda, R. T.: On the enigma of day-to-day variability in equatorial spread F, Geophys. Res. Lett., 32, L08103, doi:10.1029/2005GL022512, 2005.

Tsunoda, R. T.: Satellite traces: An ionogram signature for large scale wave structure and a precursor for equatorial spread F, Geophys. Res. Lett., 35, L20110, doi:10.1029/2008GL035706, 2008.

Tsunoda, R. T.: Multi-reflected echoes: Another ionogram signature of large-scale wave structure, Geophys. Res. Lett., 36, L01102, doi:10.1029/2008GL036221, 2009.
Tsunoda, R. T. and Ecklund, W. L.: On the post-sunset rise of the equatorial $\mathrm{F}$ layer and superposed upwelling and bubbles, Geophys. Res. Lett., 34, L04101, doi:10.1029/2006GL028832, 2007.

Valladares, C. E., Hanson, W. B., McClure, J. F., and Cragin, B. L.: Bottomside sinusoidal irregularities in the equatorial $\mathrm{F}$ region, J. Geophys. Res., 88, 8025-8042, 1983.

Whalen, J. A.: An equatorial bubble: Its evolution observed in relation to bottomside spread $\mathrm{F}$ and to the Appleton anomaly, J. Geophys. Res., 105, 5303-5315, 2000.

Wright, R. W. H.: Geomorphology of spread F and characteristics of equatorial spread F, J. Geophys. Res., 64, 2203-2207, 1959. 